\title{
Qual é o lugar da Base?
}

\author{
What is the Basis place?
}

Quel est le lieu de base?

Teodoro Adriano Costa Zanardi ${ }^{1}$

Pontifícia Universidade Católica de Minas Gerais

\begin{abstract}
Resumo: Este trabalho pretende trazer como a lógica do capital se faz presente sem qualquer pudor no período vivido pós-golpe de 2016, tendo a Base Nacional Comum Curricular como pano de fundo de políticas públicas educacionais que se propõem a intensificar às desigualdades responsabilizando escolas públicas, professores/as e estudantes pela (má) qualidade da educação brasileira. Através de referências comprometidas com o desvelamento da desigualdade, inerente ao capitalismo e fundados na tese marxiana contra Feuerbach, adotamos a teoria crítica como fundamento não só para interpretar o contexto atual, mas, também, para colaborar com ações que potencializem o papel de transformação social da educação inspirado especialmente em Paulo Freire. Problematizar a proposta de Base Nacional Comum Curricular, sua concepção curricular e como o/a professor/a comprometido com a emancipação e transformação social é, portanto, o objetivo desse ensaio que deseja colocar esse documento em seu lugar quando falamos de Educação para a transformação social.
\end{abstract}

Palavras-chave: Base Nacional Comum Curricular. Currículo. Capitalismo. Paulo Freire.

Abstract: This paper intends to show how the logic of capital is present without any modesty in the post-coup period of 2016, with the National Curricular Common Base as the background of public educational policies that aims to intensify inequalities by holding public schools accountable, teachers and students for the (poor) quality of Brazilian education. Through references committed to the unveiling of inequality, inherent in capitalism and based on the Marxian thesis against Feuerbach, we adopt critical theory as a foundation not only to interpret the present context, but also to indicate collaborating with actions that potentiate the transformation role education especially inspired by Paulo Freire. To problematize the proposal of the National Curricular Common Base, its curricular conception and how the teacher committed to emancipation and social transformation is therefore the objective of this essay that wishes to put this document in its place when we speak of Education for transformation Social.

Keywords: National Curricular Common Base. Curriculum. Capitalism. Paulo Freire.

Résumé: Cet article a pour but de montrer comment la logique du capital est présente sans aucune modestie dans la période post-coup d'Etat de 2016, avec la base commune des programmes nationaux comme toile de fond des politiques publiques d'éducation visant à intensifier les inégalités en responsabilisant les écoles publiques, enseignants et étudiants

\footnotetext{
${ }^{1}$ Doutor em Educação pela Pontifícia Universidade Católica de São Paulo (PUC/SP). Professor Adjunto do Programa de Pós-graduação da Pontifícia Universidade Católica de Minas Gerais (PUC/MG). Líder do Grupo de Pesquisa: Currículo crítico, educação transformadora: políticas e práticas. E-mail: zanardi@pucminas.br.
} 
pour la qualité (médiocre) de l'éducation brésilienne. A travers des références engagées dans le dévoilement des inégalités, inhérentes au capitalisme et fondées sur la thèse marxienne contre Feuerbach, nous adoptons la théorie critique comme fondement non seulement pour interpréter le contexte actuel, mais également pour indiquer une collaboration avec des actions qui potentialisent le rôle de transformation de l'éducation en particulier. inspiré par Paulo Freire. Diffuser la proposition de la base commune du curriculum nationale, sa conception curriculaire et la façon dont l'enseignant engagé dans l'émancipation et la transformation sociale est donc l'objectif de cet essai qui souhaite mettre ce document à sa place lorsque l'on parle d'éducation à la transformation sociale.

Mots-clés: Base commune des programmes nationaux. Programme d'études. Capitalisme. Paulo Freire.

Recebido em: 12 de abril de 2019 Aceito em: 02 de maio de 2019

\section{Introdução}

A Base Nacional Comum Curricular (BNCC) da Educação Básica, especialmente da Educação Infantil e do Ensino Fundamental homologada no final de 2017, merece ser colocada em seu (devido) lugar quando assumimos o compromisso com uma proposta de currículo emancipatória, comprometida com a diversidade e a transformação e sob uma perspectiva freireana.

Fruto de um processo que se arrastou por quase trinta anos, pois está prevista na Constituição da República Federativa do Brasil de 1988, a BNCC se constitui como um projeto normativo que impõe um documento prescritivo de competências, habilidades, conteúdos, ou, como a mesma denomina, direitos de aprendizagem (MEC, 2018).

A proposta aqui é buscar o desvelamento da proposta de BNCC trazida com sua homologação e apresentá-la a partir de políticas públicas educacionais que não podem ser interpretadas fora de um contexto mais amplo que é o da radicalização do neoliberalismo promovido pelo Golpe de $2016^{2}$.

\footnotetext{
${ }^{2} \mathrm{O}$ principal argumento apresentado para o impeachment/golpe foi o crime de responsabilidade em razão das "pedaladas fiscais" que são "o apelido dado ao 'sistemático atraso nos repasses de recursos do Tesouro Nacional', de modo que o Banco do Brasil, a Caixa Econômica Federal e o Banco Nacional de Desenvolvimento Econômico e Social (BNDES) acabam arcando com o pagamento de benefícios sociais como Bolsa-Família, Minha Casa Minha Vida, Seguro Desemprego, entre outros. (...) a potencialidade lesiva das 'pedaladas' da Presidente Dilma é temerosamente superior (aos governos anteriores). Demonstra o descontrole financeiro do governo e o descuido no que tange à condução dos gastos públicos. Há indícios de que tais condutas continuaram ocorrendo em 2015, de acordo com o acórdão n. 825/2015 do TCU, e as consequências disso devem ser analisadas com cautela. Ademais, considera-se antitransparente a atitude de não declarar tais inadimplências no rol de passivos da Dívida Líquida do Setor Público. Enquanto as instituições financeiras
} 
Não se ignora que a Base Nacional Comum Curricular seja um projeto anterior ao Golpe e que já se constituía em pilar para as políticas educacionais como prescreviam a já citada Constituição de 1988 e o próprio Plano Nacional de Educação de 2014. No entanto, não se pode ignorar que o radicalismo neoliberal e suas políticas que aprofundam a desigualdade trazido pelo Golpe de 2016, permite-nos perceber um currículo unificado que promove o aumento das responsabilidades das escolas públicas, professores/as e estudantes, que são penalizadas com cortes de investimentos, precarização do trabalho docente e condições adversas para o desenvolvimento de uma educação de qualidade.

Assim como devemos atentar para o invisível deslocamento das placas continentais que flutuam sobre o núcleo fundido da Terra para explicar terremotos e as erupções vulcânicas,

também não podemos entender, as repentinas crises econômicas e sociais, por exemplo, da maioria dos países latino-americanos, sem dirigir a nossa atenção às novas situações que estão sendo criadas pelo fenômeno da mundialização da economia, ou, mais concretamente, pela "desnacionalização" dos capitais e seu incontrolado universalismo. (SANTOMÉ, 2003, p. 20).

Assumindo o compromisso de desvelar o que está por trás desse movimento que se estabelece com a BNCC, compreendemos que não basta interpretar o seu papel diante das condições impostas à educação escolarizada, mas, a partir de Marx (2007), é necessário buscar apresentar ferramentas à praxis educadora com a construção de uma proposta contrahegemônica de currículo emancipatório.

A proposta é investigar as causas políticas da produção de uma Base Nacional Comum Curricular perquirindo sobre as políticas públicas sociais, econômicas e educacionais que se encontram na pauta do Golpe de 2016, ou seja, a lógica do capital no cenário brasileiro, os conceitos de currículo em jogo e as possibilidades de enfrentamento de uma Base Nacional Comum Curricular excludente, centralizadora, conservadora e ideologicamente comprometida com o fundamentalismo religioso.

\footnotetext{
lançavam seus créditos que tinham contra o Governo Federal, este ocultou seus débitos, criando uma sensação equivocada de regularidade que veio muito a calhar em 2014, afinal, escondeu-se um quadro de inadimplência de valores vultuosos justamente no ano eleitoral. Não obstante tais considerações, o fato é que tais condutas, por mais reprováveis que sejam (e isso vai depender de quem analisa), não constituem crime de responsabilidade (e isso é um fato), por faltar a tipificação na Lei n. 1.079/50, daí o impeachment não poder ser fundamentado nas 'pedaladas fiscais'. (SALES, 2017, p.68-75)
} 


\section{As políticas educacionais e curriculares no Brasil Pós-golpe}

O discurso da crise econômica brasileira e da corrupção endêmica do capitalismo brasileiro proporcionaram condições adequadas para a ruptura da frágil democracia que se estabeleceu após a Constituição Federal de 1988 com a Nova República.

Os tempos de redução da pobreza e de construção de direitos tiveram um curto período de avanço (2003-2014) que foram interrompidos por mais uma crise do capitalismo brasileiro. Crise que é cíclica e estrutural, como acentua David Harvey,

Crises são essenciais para a reprodução do capitalismo. É no desenrolar das crises que as instabilidades capitalistas são confrontadas, remodeladas e reformuladas para criar uma nova versão daquilo em que consiste o capitalismo. Muita coisa é derrubada e destruída para dar lugar ao novo. (HARVEY, 2016, p. 09).

As crises são oportunidades para reformas que aprofundam as desigualdades, proporcionando medidas que restringem os direitos em prol dos privilégios. Verbas para programas sociais são cortadas, aumento vertiginoso do desemprego e medidas que poderiam equalizar o acesso à educação são inibidas prol da maximização dos lucros de poucos e manutenção das desigualdades, ou melhor, aprofundamento das desigualdades.

Nesse sentido, o Golpe parlamentar-jurídico-midiático de 2016 deixa marcas indeléveis nas políticas públicas brasileiras em seu aniversário de dois anos. A Emenda Constitucional $^{3}$ que congela os gastos públicos, a reforma trabalhista com a perda de direitos para os empregados/as, a redução drástica do financiamento para aquisição de casas populares (Minha casa, Minha vida), a redução do Bolsa Família, o estancamento da Reforma Agrária, a Intervenção Militar no Rio de Janeiro, a proposta de Reforma Previdenciária, dentre outras iniciativas, fazem parte de um pacote de políticas comprometidas com a concentração de renda e aumento da pobreza com a retirada de direitos dos trabalhadores.

Nesse contexto, o governo pós-golpe tem na educação políticas públicas alinhadas com os interesses do capital frente ao sistema educacional público brasileiro. A Reforma do Ensino Médio, o desinvestimento nas Universidades Públicas, a redução de programas de

\footnotetext{
${ }^{3}$ A Emenda Constitucional n. 95 (BRASIL, 2016) congelaos gastos públicos por 20 (vinte) anos e se vincula aos interesses do capital rentista e especulativo haja vista estes (interesses) serem imunes ao congelamento.
} 
financiamentos como o FIES (Fundo de Financiamento ao Estudante do Ensino Superior) e PROUNI (Programa Universidade para Todos), a redução do financiamento para Escola em Tempo Integral, a transformação do PIBID (Programa Institucional de Bolsa de Iniciação à Docência)em Programa de Residência Pedagógica e, como não poderia deixar de ser citada, a homologação de uma Base Nacional Comum Curricular se colocam como obstáculo aos direitos das classes menos favorecidas no que toca a Educação Formal. Da mesma forma, dificulta à construção de uma sociedade plural e democrática que potencializa através da educação escolarizada a transformação social.

Nesse curto espaço, não pode deixar de se registrar como a crise do capitalismo acaba por atingir radicalmente as parcas conquistas das classes trabalhadoras e traz sob aparentes medidas técnicas soluções falsamente neutras que produzem efeitos nocivos a maioria da população. Fato é que boa parte da população compreende como as pautas sociais e econômicas são danosas aos direitos dos trabalhadores. Já as políticas públicas educacionais, capitaneadas pela Base Nacional Comum Curricular, merecem uma abordagem mais cuidadosa em razão de propostas que pretensamente seriam para produzir melhores condições de vida aos/às estudantes.

Como nossa preocupação principal é a Base Nacional Comum Curricular, passamos ao seu contexto de produção. Impossível compreender a Base sem investigar o cenário desenhado pela Organização para Cooperação e Desenvolvimento Econômico (OCDE) que reconhecidamente influencia políticas públicas educacionais brasileiras, como atesta a própria BNCC em seu texto (MEC, 2018).

David Chaves explica que a BNCC é

(...) produção de organismos como a Organização para Cooperação e Desenvolvimento Econômico (OCDE). Segundo ele, a entidade é relevante porque indica ao mundo empresarial quais países estão cumprindo orientações em áreas como educação e economia, sinalizando os locais mais atrativos para investimentos privados. Uma dessas variáveis é a existência de mão de obra qualificada. Qualificada, claro, segundo os padrões estabelecidos pelo organismo. (ESCOLA POLITÉCNICA DE SAÚDE JOAQUIM VENÂNCIO, 2018)

A partir do PISA (Programme for International Student Assessment) e de pesquisas comparativas, as políticas educacionais foram se internacionalizando com base em diretrizes da OCDE que, tendo uma avaliação internacional, passou a pressionar por um currículo que permita a legitimidade dessa avaliação. 
Seguir as determinações da OCDE se constitui em referência para qualidade da educação mundial trazendo um fenômeno de ranqueamento de países que acabam por estabelecer os padrões curriculares necessários para o alcance de um desempenho comparativamente satisfatório. A OCDE, assim, passa a ocupar, para muitos países seguidores desse receituário, o lugar de Ministro da Educação Mundial.

Nesse cenário, a OCDE tem importante papel na "elaboração de discursos que estejam de acordo com os seus interesses privatistas" (SANTOMÉ, 2003. p. 19) que corroboram a perspectiva exclusivamente meritocrática de educação e deixam de lado as questões de fundo sobre as desigualdades sociais.

Da mesma forma que a OCDE traz uma pressão externa e internacional para políticas unificadoras do currículo escolar, internamente emergiu na última década movimentos empresariais capitaneados por fundações privadas dedicadas ao desenvolvimento de uma educação de qualidade. Esses personagens foram nomeados por Diane Ravitch de corporate reformers que Luiz Carlos Freitas (2012) nos brindou com a tradução para reformadores empresariais.

No Brasil, movimento semelhante tem coordenado a ação dos empresários no campo da educação e é conhecido como Todos pela Educação. O presidente do Conselho de Governanç, deste movimento é o megaempresário Jorge Gerdau Johannpeter, do Grupo Gerdau, que também é assessor da presidenta Dilma como coordenador da Câmara de Políticas de Gestão, Desempenho e Competitividade de seu governo. (FREITAS, 2012, p. 381).

Fundado em 2006, o Movimento Todos pela Educação tem como apoiadores, parceiros e mantenedores, por exemplo, a Fundação Bradesco, Itaú Social, Fundação Lehmann, Instituto Unibanco, Instituto Natura, Rede Globo, Fundação Roberto Marinho, BID (Banco Interamericano de Desenvolvimento), Fundação Santillana, Fundação Victor Civita, dentre outros. (TODOS PELA EDUCAÇÃO, 2018).

Nascido antes do Golpe e fortalecido pelo governo democrático, a Base Nacional Comum Curricular encontrou eco nos fundamentos tecnicista, meritocrático e gerencial defendidos pela lógica do capital para o desenvolvimento da qualidade da educação. E, assim, o Plano Nacional de Educação, Lei n. 13.005, de 2014 (BRASIL, 2014), trouxe a proposta de Base Nacional Comum Curricular como estratégia para o alcance da qualidade da educação, impondo um prazo de 02 (dois) anos para sua publicação. 
Como se percebe a adesão às concepções da OCDE e dos reformadores educacionais não é um privilégio do momento pós-golpe. Já se fazia presente nas políticas públicas educacionais desenvolvidas no período entendido como democrático, ou seja, no período que o Ministério da Educação aceitava as contradições que se colocam na conquista de direitos para as populações mais pobres e o fortalecimento da elite capitalista brasileira. Naquela época, faziam-se presentes representantes de movimentos sociais progressistas em vários fóruns, conselhos e instâncias de poder. Em que pese essa representatividade, posições contrárias ao estabelecimento de uma Base Nacional Comum Curricular, como exposta pela ANPED (Associação Nacional de Pós-graduação e Pesquisa em Educação) e pela ABdC (Associação Brasileira de Currículo) (ANPED, 2018), foram sumariamente ignoradas.

Mas é no contexto pós-golpe que as políticas públicas educacionais abandonaram suas contradições e se apresentaram pautadas, de forma cristalina, no tecnicismo e gerencialismo de caráter meritocrático, tendo o discurso de liberdade de escolha e igualdade de oportunidades ocupado toda a propaganda das apressadas reformas, que no caso do Ensino Médio se iniciou através de Medida Provisória (BRASIL, 2018).

Utilizando-se do discurso da crise, sem revelar suas causas estruturais, o governo golpista trouxe medidas para melhorar a qualidade da educação dentro da pauta estabelecida por reformadores educacionais, OCDE e conservadores que formam sua base de apoio. Movimentos sociais e entidades acadêmicas foram relegadas ao olvido nos novos contornos que tomou o MEC (Ministério da Educação).

O conteúdo da Base Nacional Comum Curricular, que era objeto de lutas ideológicas no tocante especialmente às questões afro-brasileiras e indígenas, de gênero e sobre a alfabetização, por exemplo, passou a responder ao conservadorismo com uma versão aprovada pelo Conselho Nacional de Educação com dois votos contrários.

O Ministério da Educação, na fala de seu Ministro a época, assim se posicionou após a aprovação:

"Com a BNCC, o Brasil se alinha aos melhores e mais qualificados sistemas educacionais do mundo, que já se organizam em torno de uma base comum”, destacou o ministro Mendonça Filho, ao explicar que o texto aprovado no CNE passará por revisão técnica e análise jurídica no MEC antes da homologação. "Vamos entregar aos brasileiros um texto plural e contemporâneo, que terá papel crucial na melhoria da qualidade e da equidade da educação no Brasil”, garantiu o ministro. (MEC, 2018b). 
Comemorou o alinhamento com sistemas educacionais do mundo e expos sua visão estreita de pluralidade dentro do comum e centralizador. A versão da BNCC aprovada, além de problemas de concepção, que serão tratados no próximo capítulo, traz uma seleção comprometida com o eurocentrismo como direitos de aprendizagens na disciplina de História, antecipação do processo de Alfabetização para o Ensino Infantil como forma de responsabilização e pressão sobre professores/as e escolas públicas; abandona questões de gênero e étnico-raciais em prol de multiculturalismo liberal, sendo que as Histórias e Culturas Afro-brasileira e Indígenas ocupam mais notas de rodapé do que o próprio corpo da BNCC (MEC, 2018); e insere o Ensino Religioso no Ensino Fundamental como forma de atender interesses de grupos fundamentalistas religiosos que desejam ver na escola pública espaço para expansão de suas crenças..

\section{Base Nacional Comum Curricular é currículo?}

A BNCC traz uma concepção de currículo travestida de direitos de aprendizagens que, sob a ótica tecnicista e meritocrática, constituem-se em deveres de aprendizagens. Obviamente não é possível reduzir toda a complexidade do currículo às prescrições contidas no documento homologado pelo governo golpista. No entanto, não é possível cultivar a ingenuidade que o discurso de igualdade de aprendizagens e de oportunidades, por consequência, não resultará em uma forte pressão para a reformulação dos currículos, especialmente ou mesmo exclusivamente das redes públicas de ensino.

Como apresentado na página inicial do sítio da BNCC na internet,

A Base estabelece conhecimentos, competências e habilidades que se espera que todos os estudantes desenvolvam ao longo da escolaridade básica. Orientada pelos princípios éticos, políticos e estéticos traçados pelas Diretrizes Curriculares Nacionais da Educação Básica, a Base soma-se aos propósitos que direcionam a educação brasileira para a formação humana integral e para a construção de uma sociedade justa, democrática e inclusiva. (MEC, 2018).

Devemos acentuar que o negrito nos conhecimentos é obra do próprio MEC que se nega a reconhecer na BNCC uma proposta de currículo, mas sim norteadora dos currículos.

No material de divulgação publicado em março de 2018, vem a seguinte concepção sobre BNCC e Currículo: 
BNCC serve como referencia para a construção e adaptação dos currículos de todas as redes de ensino do país. As redes e escolas seguem com autonomia para elaborar, por meio do currículo, metodologias de ensino, abordagens pedagógicas e avaliaç,oes, incluindo elementos da diversidade local e apontando como os temas e disciplinas se relacionam. BNCC e currículos têm, portanto, papeis complementares: a Base dá o rumo da educação, mostrando aonde se quer chegar, enquanto os currículos traçam os caminhos. (MEC, 2018a).

Em que pese a polissemia do termo currículo, na orientação do MEC, o mesmo é reduzido ao caminho(!?) e o que se deseja ensinar ("aonde quer se chegar”) é a Base Nacional Comum Curricular.

Diante dessa confusão conceitual, forçoso trazer alguns conceitos de currículo para desvelar como uma orientação curricular centralizadora e antidemocrática deseja se fazer presente (no duplo sentido) nas e para as escolas. Passamos a algumas concepções de currículo, das mais tradicionais e tecnicistas às mais progressistas e comprometidas com a emancipação e pluralidade.

Sacristán (2013) evidencia o significado de currículo mesmo explicando sobre sua complexidade. Para o autor espanhol (2013, p. 16), currículo "é aquilo que um aluno estuda". Obviamente, essa simplicidade desafia a concepção de BNCC que se furta a assumir que deseja estabelecer o que um/a aluno/a deve estudar.

A BNCC, indubitavelmente, é uma criação unificadora que organiza os direitos de aprendizagens, conhecimentos e habilidades com foco na competência compreendida "como a mobilização de conhecimentos (conceitos e procedimentos) (MEC, 2018, p. 08). A própria BNCC assume que a função das competências é orientar os currículos, ou seja, é a fonte de todos os currículos que não se orientariam mais por objetivos como defendia Ralph Tyler (1983). Ressalte-se que o caráter normativo da BNCC impõe aos currículos das redes de ensino um documento prescritivo de competências e, por consequência, de conhecimentos que estudantes devem mobilizar e estudar.

Lado outro, a insistência em um currículo por competências é desvelada pelo conjunto de habilidades elencadas pela BNCC com um nível de detalhamento que visibiliza o compromisso com o estabelecimento de um currículo nacional.

$\mathrm{O}$ que se pretende expor é que, por mais que a BNCC fuja do papel de seleção, organização e sequenciamento de conteúdos, ela assim se assume e se ela não é o currículo, ela não pode deixar se ser considerada um currículo (prescrito e unificador). 
Diante dessa perspectiva, é sabido pelos entusiastas da BNCC, como o Movimento Todos pela Educação, que a teoria curricular de Michael Young (2007) e sua defesa de um currículo nacional servem de arcabouço teórico coerente para legitimar a construção de uma Base Comum. O fundamento do conhecimento poderoso legitima a comunidade de especialistas a estabelecer uma proposta de currículo nacional em que se prescreve o conhecimento a ser escolarizado como direitos de todas as crianças e jovens no Brasil. $\mathrm{O}$ currículo é, assim, desideologizado e descontextualizado em nome de um conhecimento teórico que uma comunidade de "iluminados" é capaz de estabelecer para todas as escolas brasileiras.

Essa concepção de currículo é consoante com a lógica naturalizante e inevitável do capital, pois não problematiza a seleção cultural e ideológica que se pretende perpetuar através do projeto de escolarização. Da mesma forma, é assumido que a única forma de transformação é a individual, uma vez que é a capacidade do indivíduo mobilizar seus conhecimentos que proporcionará (ao mesmo) a melhoria de vida.

Essa confiança de Young (2007) à comunidade de especialistas é tributária de um currículo arbitrário que desconfia do potencial transformador que o contexto vivido, que o diálogo e a problematização possuem como princípios orientadores da construção curricular. Para Young, esses princípios são só mobilizadores, motivacionais e metodológicos, sendo de pouca importância para o currículo.

\section{A BNCC e seu lugar: uma perspectiva problematizadora}

Considerando que a BNCC se situa na lógica do capital e traz uma determinação curricular tecnicista, individualista e meritocrática que responsabiliza os sujeitos da escola pública pela qualidade da educação;

Considerando que sua última versão, mais do que as anteriores, estabelece uma visão mais conservadora do conhecimento a ser escolarizado e emana de um governo golpista sem nenhum compromisso com movimentos sociais;

Considerando que a BNCC é normativa, centralizadora e prescritiva das competências, conhecimentos e supostos direitos de aprendizagens e trará consequências para professores/as que atuam nas redes de ensino público de Educação Básica; 
Considerando que é necessário buscar alternativas que proporcionem articular essa proposta curricular com vivências, experiências e problematizações necessárias à transformação social e ao desvelamento das causas da desigualdade;

Considerando que a emancipação não se efetiva com a confiança em mitos salvadores e que é o diálogo horizontalizado entre oprimidos/as mediados pelo mundo que possibilita a superação da opressão, passamos aos seguintes fundamentos curriculares sob uma perspectiva freireana.

Tendo no horizonte que Paulo Freire não se debruçou sobre uma teoria curricular, mas que é inegável sua contribuição a partir de suas problematizações em relação aos saberes e conhecimentos. Desde a Pedagogia do Oprimido (2013), publicada em 1968, temas geradores, conteúdos programáticos e ação dialógica passam a influenciar teorias curriculares, especialmente as críticas. A concepção de Freire (1992; 1996; 2013) em relação ao conhecimento valoriza a realidade concreta dos sujeitos, como ponto de partida para uma construção dialógica com os conhecimentos científicos, os quais o autor chama de conhecimentos-padrão. Em obra escrita com Ira Shor, Paulo Freire sintetiza com precisão sua concepção:

10 chamado "padrão" é um conceito profundamente ideológico, mas é necessário ensinar a sua utilização enquanto se criticam, também, suas implicações políticas. Agora, a questão é a seguinte: sabendo de tudo isso, terá o professor libertador o direito de não ensinar as formas padronizadas? Terá o direito de dizer: "Sou um revolucionário, portanto, eu não ensino o 'bom' inglês?” Não. Do meu ponto de vista, o educador deverá tornar possível o domínio, pelos estudantes, do inglês padrão, mas - e aqui está a grande diferença entre ele e outro professor reacionário - enquanto o professor tradicional ensina as regras do inglês de primeira (risadas), ele acentua a dominação dos estudantes pela ideologia elitista, que está inserida nessas regras. O professor libertador lhes ensina a forma padronizada, para que possam sobreviver, discutindo com eles todos os ingredientes ideológicos dessa ingrata tarefa. Você está vendo? Acho que é dessa forma que os professores podem refletir sobre o medo que eles têm da rejeição dos estudantes e também sobre o medo que têm das formas padronizadas (FREIRE; SHOR, 1986, p.49).

Para Freire o educador progressista não pode sonegar esse conhecimento padrão aos/às educandos/as. Na Pedagogia da Esperança (1992), Freire faz uma defesa da transição da curiosidade ingênua para a criticidade como fator fundamental para a emancipação dos educandos.

Sob uma perspectiva freireana não há o desprezo ao conhecimento acumulado historicamente, mas um cuidado democrático e dialógico na construção da proposta 
curricular. A problematização e a horizontalização das relações são fundamentos de um diálogo que se pretende emancipatório em uma proposta curricular.

É necessário rejeitar uma relação em que o $E u$ conhece e $T u$ não conhece. A lógica bancária se enquadra em um trabalho com a BNCC em que o/a educador/a deve conhecer esta e transmiti-la aos/às educandos/as em uma relação que o mundo é de conhecimento do/a educador/a e é, através dele/a educador/a, que o/a educando/a conhecerá o mundo.

Uma percepção libertadora de currículo se desenvolve na relação $E u$-Tu mediada pelo mundo (FREIRE, 2013), ou seja, Educando/a-Educador/a são mediados pelo mundo vivido com suas experiências e saberes. Um mundo onde o conhecimento/competências contidos na BNCC não se constituem em a priori. A participação dos conhecimentos acumulados historicamente (BNCC) deve se fazer presente nessa relação quando oferece explicações para a problematização que se estabelece nesse diálogo.

$\mathrm{O} / \mathrm{a}$ educador/a não precisa rejeitar a priori a $\mathrm{BNCC}$, mas lançar um olhar crítico para suas possibilidades de explicações do mundo problematizado em sala de aula. A BNCC não é o mundo que vai fazer a mediação na relação $E u$-Tu, mas tão somente mais uma seleção interessada de explicações.

\section{Considerações finais}

Em síntese, temos o conhecimento-padrão, ou conhecimento científico, ou conhecimento historicamente acumulado, ou a Base Nacional Comum Curricular como uma proposta curricular que pode servir de subsídio para educadores/as comprometidos com o desvelamento do mundo. Uma que se coloca ao lado do cotidiano, das experiências vividas, das problematizações não respondidas, das violências sofridas, das desigualdades naturalizadas, que necessitam ser incorporadas ao conhecimento a ser escolarizado.

Porém, necessário enfatizar que seu compromisso com a lógica do capital nos leva a desconfiar de suas potencialidades, sendo muito mais recomendável confiar no diálogo problematizador como forma de desvelar as desigualdades e colaborar com a emancipação.

\section{Referências}

ANPED. Exposição de motivos sobre a Base Nacional Comum Curricular. Disponível em $<$ http://www.anped.org.br/sites/default/files/resources/Of_cio_O1_2015_CNE_BNCC.pdf $>$ Acesso em 18 mar. 2018. 
BRASIL. Lei n. 13.005, de 25 de junho de 2014. Aprova o Plano Nacional de Educação - PNE e dá outras providências. Disponível em <http://www.planalto.gov.br/ccivil_03/_ato20112014/2014/lei/113005.htm?TSPD_101_Ro=aa9302582cfb739a66547890a36b7866cJfooooo 00000000000d6fa48bbffffo0000000000000000000000000005aaee22 1006ad35760> Acesso em 18 mar. 2018.

BRASIL. Medida provisória n. 746, de 2016. Disponível em <https://www.congressonacional.leg.br/materias/medidas-provisorias/-/mpv/126992> Acesso em 18 mar. 2018.

ESCOLA POLITÉCNICA DE SAÚDE JOAQUIM VENÂNCIO. A quem interessa a BNCC? Disponível em < http://www.epsjv.fiocruz.br/noticias/reportagem/a-quem-interessa-abncc > Acesso em 16 mar. 2018.

FREIRE, Paulo. SHOR, Ira. Medo e Ousadia - O Cotidiano do Professor. Rio de Janeiro: Paz e Terra, 1986.

FREIRE, Paulo. Pedagogia da Esperança. 11. ed. São Paulo: Paz e Terra, 1992.

FREIRE, Paulo. Pedagogia da autonomia: saberes necessários à prática educativa. São Paulo: Paz e Terra, 1996.

FREIRE, Paulo. Pedagogia do oprimido. 33.ed. Rio de Janeiro: Paz e Terra, 2013.

FREITAS, Luiz Carlos. Os reformadores empresariais da educação: da desmoralização do magistério à destruição do sistema público de educação . Educação e Sociedade, Campinas, v. 33, n. 119, p. 379-404, abr.-jun. 2012

HARVEY, David. 17 contradições e o fim do capitalismo. São Paulo: Boitempo, 2016.

LÓWY, Michael. A teoria da revolução no jovem Marx. São Paulo: Boitempo, 2012.

MARX, Karl; ENGELS, Friedrich. A ideologia alemã : crítica da mais recente filosofia alemã em seus representantes Feuerbach, B. Bauer e Stirner, e do socialismo alemão em seus diferentes profetas. São Paulo: Boitempo, 2007.

MEC. Base Nacional Comum Curricular. Disponível em $<$ http:/ portal.mec.gov.br/index.php?option=com_docman\&view =download\&alias $=79601-$ anexo-texto-bncc-reexportado-pdf-2\&category_slug=dezembro-2017-pdf\&Itemid=30192> Acesso em 16 mar. 2018.

MEC. Dia D: Dia Nacional de discussão sobre a BNCC. Disponível em $<$ http://basenacionalcomum.mec.gov.br/wp-content/uploads/2018/03/2-roteiro-paraatividades.pdf> Acesso em 19 mar. 2018 a.

MEC. Base Nacional Comum Curricular é aprovada no CNE e segue para homologação do ministro da Educação. Disponível em < http://portal.mec.gov.br/ultimas-noticias/211$218175739 / 5854$ 1-base-nacional-comum-curricular-e-aprovada-no-cne-e-segue-parahomologacao-do-ministro-da-educacao > Acesso em 20 abr. 2018. 
SACRISTÁN, José Gimeno. O que significa currículo? In: SACRISTÁN, José Gimeno (org.). Saberes e incertezas sobre o currículo. Porto Alegre: Penso, 2013.

SANTOMÉ, Jurjo Torres. A educação em tempos de neoliberalismo. Porto Alegre: Artmed, 2003.

TODOS PELA EDUCAÇÃO. Mantenedores e apoiadores. Disponível em $<$ https://www.todospelaeducacao.org.br/quem-somos/mantenedores-e-apoiadores/> Acesso em 18 mar. 2018.

TYLER, Ralph W. Princípios básicos de currículos e ensino. 7. ed. Rio de Janeiro: Globo, 1983.

YOUNG, Michael F. D. Para que servem as escolas? Educação e Sociedade, vol. 28, n. 101. Campinas: set./dez. 2007.

SALES, Tainah. Aspectos jurídicos do impeachment, dos crimes de responsabilidade e das “pedaladas ficais”. Revista de Direito Brasileira. V. 16. n. 7. São Paulo, jan./abr., 2017 